\title{
Interstitial de novo 18q22.3q23 deletion: clinical, neuroradiological and molecular characterization of a new case and review of the literature
}

Elisa Tassano ${ }^{1 *}$, Mariasavina Severino ${ }^{2}$, Silvia Rosina ${ }^{3}$, Riccardo Papa $^{3}$, Domenico Tortora $^{2}$, Giorgio Gimelli ${ }^{1}$, Cristina Cuoco ${ }^{1}$ and Paolo Picco ${ }^{3}$

\begin{abstract}
Background: Deletions of the long arm of chromosome 18 cause a common autosomal syndrome clinically characterized by a protean clinical phenotype.

Case presentation: We report on a 16-month-old male infant affected by fever attacks apparently unrelated with any infectious or inflammatory symptoms, growth retardation, bilateral vertical talus, congenital aural atresia, dysmorphisms, mild psychomotor delay, and peculiar neuroradiological features. Array-CGH analysis revealed one of the smallest 18q22.3q23 interstitial deletions involving five genes: TSHZ1, ZNF516, ZNF236, MBP, and GALR1.

Conclusions: Herein we focus on previously unreported heralding symptoms and neuroradiological abnormalities which enlarge the spectrum of $18 \mathrm{q}$ deletion syndrome demonstrating that a small deletion can determine a complex phenotype.
\end{abstract}

Keywords: 18q- syndrome, Array CGH, Brain MRI, Spectroscopy, Diffusion tensor imaging, Radial diffusivity

\section{Background}

Deletions of the long arm of chromosome 18 (18q-) described by De Grouchy et al. [1] cause a common autosomal syndrome (1:40,000 live births) [2] characterized by a wide range of phenotypic abnormalities related to the size of the deletion and the position of breakpoints. Common clinical features of the 18q- syndrome are short stature, facial dysmorphisms, foot deformities, congenital aural atresia without microtia, variable intellectual disability, cerebral white matter abnormalities, and microcephaly [3, 4]. Less commonly reported features are kidney malformations, bone dysplasia, growth hormone deficiency, congenital heart disease (atrial or septal defect), and skin manifestations (dimpling and excessive whorls on fingertips) [5]. Besides cognitive impairment, neurological abnormalities

\footnotetext{
* Correspondence: eli.tassano@gmail.com; elisatassano@ospedale-gaslini.ge.it 'Laboratorio di Citogenetica, Istituto Giannina Gaslini, L.go G.Gaslini 5, 16147 Genoa, Italy

Full list of author information is available at the end of the article
}

may include hypotonia, seizures, nystagmus, poor coordination, tremor, and choreoathetosis.

Several studies tried to define the specific regions involved in each phenotypic trait and to identify possible candidate genes [4, 6-11].

The advent of high-resolution microarray comparative hybridization $(\mathrm{aCGH})$ has allowed more precise phenotype/genotype correlations of such protean syndrome. Interestingly, aCGH analysis performed in a series of 189 patients with deletions of chromosome 18q revealed that none of the unrelated individuals shared the same breakpoints, demonstrating a high level of variability and genomic complexity surrounding deletions of 18q [12].

Herein we report a patient with one of the smallest 18q22.3q23 interstitial deletions described so far, focusing on the heralding symptoms and the advanced neuroradiological findings. These factors, together with genetic assessment, can improve our knowledge about this group of patients. 


\section{Case presentation}

We report the case of a 2-year-old male born at term after an uneventful pregnancy from healthy unrelated parents (Fig. 1). The family history was unremarkable. At birth his weight was $2.990 \mathrm{~kg}$ (10th centile), length was $48 \mathrm{~cm}$ (6th centile), and head circumference was $33 \mathrm{~cm}$ (6th centile). Apgar scores were 8 and 9. Bilateral congenital vertical talus was present at birth. Motor development was delayed (autonomous sitting acquired at 13-14 months of age). From the age of 5 months, the patient presented long-term fever attacks with a continuous/sub-continuous pattern and spikes up to $40-41{ }^{\circ} \mathrm{C}$, apparently not associated with any infectious or inflammatory manifestation. Acute phase reactants were persistently within normal ranges. The only reported concomitant symptoms were hyporexia and poor weight gain. Neither antipyretic nor antibiotic treatment seemed to be effective.

At the age of 16 months the patient was admitted to our Unit for fever of unrecognized origin. Physical examination revealed growth impairment: weight was $7.83 \mathrm{~kg}(<3$ th centile), length was $73 \mathrm{~cm}(<3$ th centile, SDS -2.5$)$ with a BMI of 14.7 (-2.3 SDS). Mild dysmorphic features were present (i.e. frontal bossing, low-set ears), dental eruption was regular although he showed mild organ enamel dysplasia. Neurologic assessment showed global hypotonia, hyperlaxity, hyporeflexia, and motor delay (he could only walk with support). During hospitalization, we documented recurrent abrupt fever spikes (up to $39^{\circ} \mathrm{C}$ ) lasting 3-5 days, without any other systemic or local sign of inflammation or infection. Fever attacks were well tolerated; skin hyperthermia and sweating were present too. Laboratory investigations showed inflammatory parameters within normal ranges also during fever spikes, mild microcytic anaemia (Hb $11.8 \mathrm{~g} / \mathrm{dl}, \mathrm{MCV} 72 \mathrm{fL}$ ), partial IgA deficiency (27 mg/ dl) with normal IgM and IgG, normal lymphocyte subpopulations, and normal immune response against vaccines.

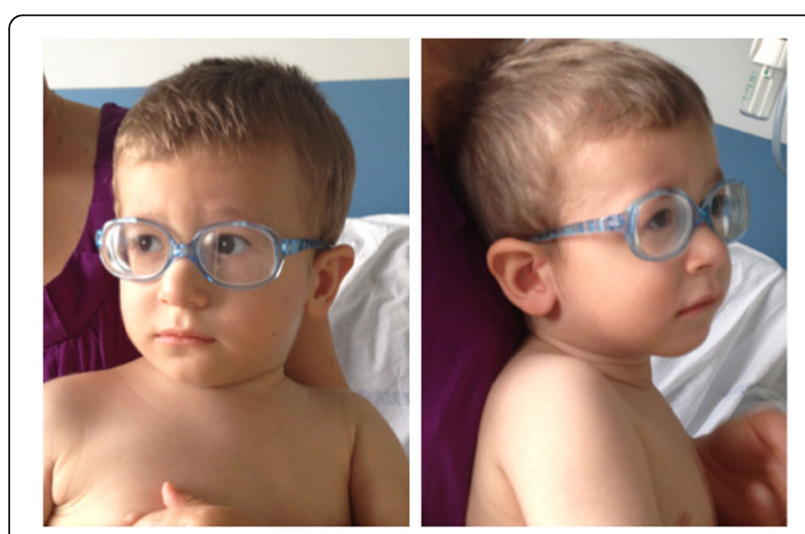

Fig. 1 Picture of the patient performed at 14 months demonstrates epicanthal folds, smooth philtrum, thin upper lip, low-set ears, prominent frontal bossing and sparse light hair, carp-shaped mouth
The infectious disease workout was negative: only once a low degree bacteriuria (below $50.000 \mathrm{UFC} / \mathrm{ml}$ ) was incidentally found and antibiotic therapy (amoxicillin-clavulanic acid) was started without any efficacy against the fever. Abdominal and renal tract ultrasound scan, cystomanometry, renal scintigraphy and voiding cystography, chest $\mathrm{X}$-ray, echocardiography, and single-contrast esophagogastroduodenal X-ray were also normal. Thyroid hormones, acylcarnitine profile, plasma lactate, urinary catecholamine, organic acid, and mevalonate urinary concentrations resulted within normal ranges. Brain MRI showed diffuse white matter signal hyperintensity on T2-weighted images in keeping with delayed myelination. Visual evoked potentials showed latency of cortical components at the upper limit of normal ranges, and somatosensory evoked potentials revealed a conduction velocity at the upper limit of normal ranges for age with regular latency of cortical, subcortical, cervical, and peripheral components in the upper limbs. Ophthalmologic evaluation revealed high degree myopia. Otologic examination disclosed stenosis of the external auditory canals without structural abnormalities of the pinna. Behavioural hearing assessment demonstrated bilateral hearing impairment. CT scan of the temporal bone confirmed bilateral atresia of the membranous portions and marked stenosis of the bony portions of the external auditory canals (Fig. 2).

At the age of 24 months, the patient was re-evaluated. Growth impairment persisted: weight was $8.5 \mathrm{~kg}(<3$ th centile), length was $82 \mathrm{~cm}$ (SDS -1.5) with a BMI of 12.6 (-4.3 SDS); psychomotor delay persisted (e.g. walking was possible with an enlarged basis, no verbal expression was reported). Notably, fever attacks had spontaneously disappeared from the age of 20 months. A follow-up brain MRI at this age demonstrated an unchanged pattern of abnormal intensity of the white matter on T2-weighted images (Fig. 3a).

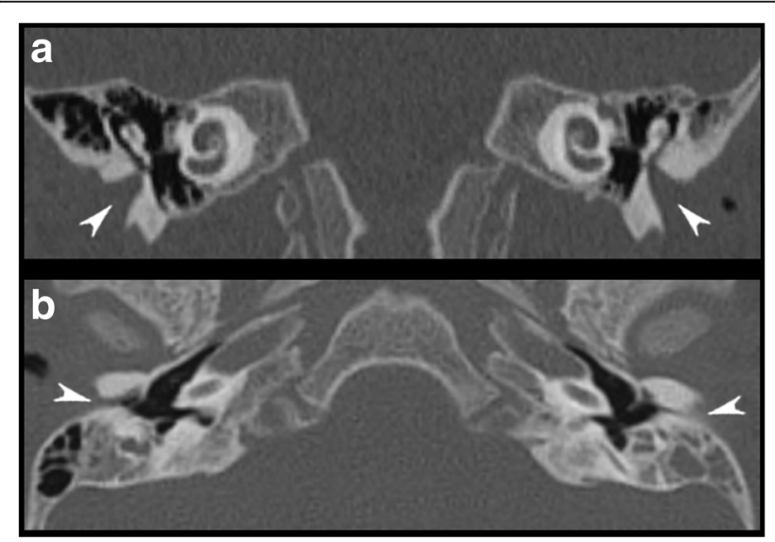

Fig. 2 Temporal bone CT. Coronal (a) and axial (b) images reveal marked stenosis and peculiar vertical orientation of the bony portions of the external auditory canals (arrowheads) associated with rotation and fusion of the malleus to the lateral middle ear cavity wall 


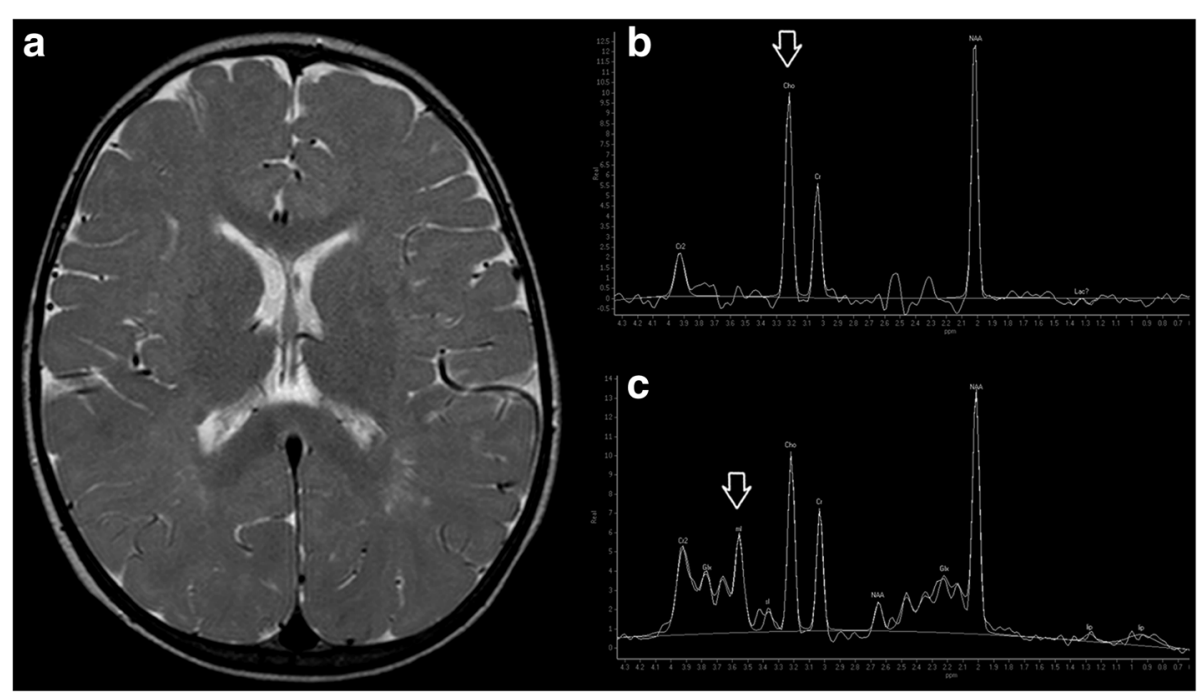

Fig. 3 Brain MRI and MR spectroscopy performed at 24 months of age. a Axial T2-weighted image shows diffuse hyperintensity of the cerebral white matter with relative sparing of the corpus callosum. Long TE spectroscopy (b) reveals an elevated choline peak (arrow), while short TE spectroscopy (c) demonstrates a slightly increased myoinositol peak (arrow)

\section{Results}

\section{Genetic study}

Array-CGH analysis of the patient showed an interstitial deletion at 18q22.3q23 spanning about $2.5 \mathrm{Mb}$ of genomic DNA from position 72,887,342 bp (clone A_16_P20921235) to $75,418,267$ (clone A_16_P41107360) flanked by probe
A_16_P20921038 (72,818,369 bp) and probe A_14_P133188 $(75,452,546 \mathrm{bp})$ according to UCSC Genome Browser (GRCh37/hg19 assembly) (Fig. 4). The deleted region contains 5 OMIM genes: TSHZ1 (MIM 1614427, Teashirt zinc finger homeobox), ZNF516 (MIM 615114, Zinc finger protein 516), ZNF236 (MIM 604760, Zinc finger protein-236),

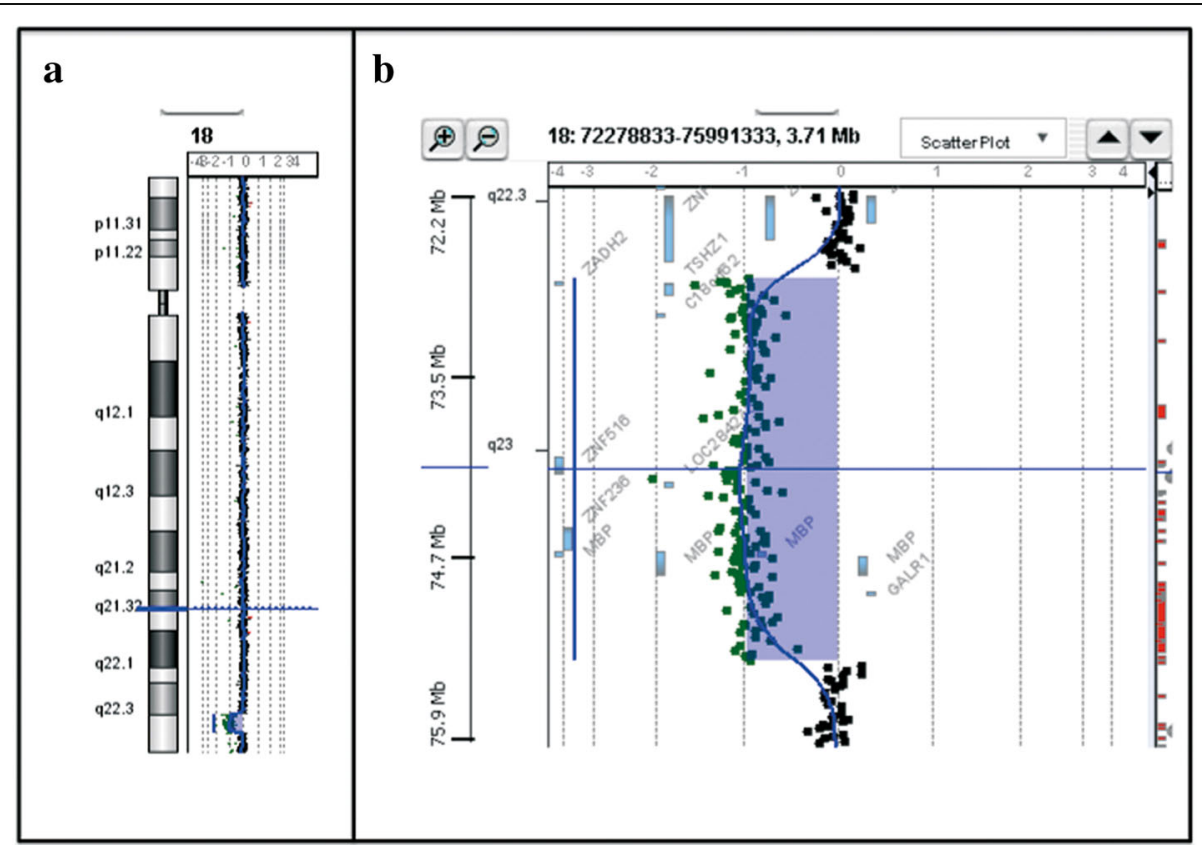

Fig. 4 Results of array-CGH analysis. a Chromosomal view. b Zoom view of long arm of chromosome 18 shows a $2.5 \mathrm{Mb}$ deletion at $18 \mathrm{q} 22.3 \mathrm{q} 23$ spanning from position 72,887,342 bp (clone A_16_P20921235) to 75,418,267 (clone A_16_P41107360) flanked by probe A_16_P20921038 (72,818,369 bp) and probe A_14_P133188 (75,452,546 bp) according to UCSC Genome Browser (hg19; GRChBuild 37.1, February 2009) 
MBP (MIM 159430, Myelin basic protein), GALR1 (MIM 600377, Galanin receptor 1). Array-CGH of the parents was normal.

\section{Neuroimaging data}

Analysis of the DTI scalars revealed slightly lower fractional anisotropy and higher mean, radial, and axial diffusivity in the patient compared to controls in all the assessed white matter regions. However, these differences were not statistically significant as assessed by non-parametric Mann-Whitney test (Table 1).

MRS demonstrated normal $\mathrm{N}$-acetyl aspartate, absent lipids and lactate, and increased choline peak on the long TE sequence with $\mathrm{N}$-acetyl aspartate/creatine and choline/creatine ratios of 2.18 and 1.79 , respectively. On the short TE sequence, slight increase of the myoinositol peak was noted with $\mathrm{N}$-acetyl aspartate/creatine and choline/ creatine ratios of 2.12 and 1.44, respectively (Fig. 3b, c).

\section{Discussion}

Here we describe the peculiar clinical phenotype and neuroradiological features of a child harbouring an uncommon 18q22.3q23 interstitial microdeletion.

To our knowledge, this is one of the smallest $18 \mathrm{q}$ interstitial deletions described so far, including five OMIM genes: TSHZ1, MBP, ZNF516, GALR1, and ZNF236. Among these genes, TSHZ1 and MBP were considered dosage-sensitive either with high or low penetrance of the abnormal phenotype, the haploinsufficiency of ZNF516 and GALR1 seemed unrelated with the clinical manifestations of $18 \mathrm{q}$ - syndrome, while the consequences of a copy number change of ZNF236 are still unknown [5] (http://www.pediatrics.uthscsa.edu/ centers/Chromosome18/dosage.asp). Only three other patients harbouring a very similar deletion and similar breakpoints have been reported $[[3,12]$, case 1 ; [13], case 2]. Phenotypically, all showed dysmorphic features and CAA, three patients showed intellectual disability and only two a growth retardation (Table 2). Interestingly, all of them shared the deletion of TSHZ1 and $M B P$ genes.

TSHZ1 gene is a member of the teashirt-type zinc-finger protein family encoding putative zinc finger transcription factors. Targeted inactivation in mouse resulted in a neonatal lethal phenotype with soft palate clefting, vertebral malformations, and abnormalities of the middle ear [14]. In particular, the inactivation of Tshz1 seemed to lead to the deregulation of Cbfa1 (RUNX2) in mesenchymal condensation, which allows the development of the tympanic ring. Therefore, the hemizygosity of TSHZ1 gene was indicated as a possible candidate for aural atresia in humans [13]. Recently, it has been demonstrated that deletion of TSHZ1 in mice leads to olfactory bulb hypoplasia and severe olfactory impairment [15]. This gene has been proposed as a candidate gene for congenital vertical talus (CVT) in a study on three patients with 18q deletions [3]. Notably, congenital aural atresia without microtia and CVT were also found in our patient, thus supporting the hypothesis of a pivotal role of TSHZ1 in the development of ears and feet [[3, 12], case 1, [13], case 2].

$M B P$ gene encodes a myelin basic protein that represents one of the most important structural proteins of the myelin sheath. In particular, $M B P$ is thought to play a major role in myelin compaction. Brain MRI studies in patients with 18q- syndrome typically showed diffuse white matter T2 hyperintensity with poor differentiation between gray and white matter $[16,17]$. These findings have been interpreted as delayed or reduced myelin formation related to haploinsufficiency of the $M B P$ gene. However, the precise pathogenetic mechanisms underlying white matter abnormalities in 18q- syndrome remain poorly understood. Loss of both $M B P$ genes in homozygous shiverer (shi) mice was histologically characterised by almost complete absence of myelin in the central nervous system [18]. However, heterozygous shiverer mice were found clinically normal with normal myelin on brain MRI and pathological examination $[19,20]$. Interestingly, a recent autopsy study on a 6 -year-old boy with 18q- syndrome and abnormal white matter on brain MRI revealed prominent astrogliosis with normal myelin fibers and compact myelin sheaths [21]. Immunohistological examination revealed normal MBP immunoreactivity in myelinated fibers, but reduced immunoreactivity in oligodendrocytes. The authors therefore suggested that the signal abnormalities exhibited in 18qsyndrome could reflect astrogliosis rather than hypomyelination [21]. This hypothesis is supported by the increase

Table 1 Diffusion Tensor Imaging data in the present patient compared with 5 age-matched controls

\begin{tabular}{|c|c|c|c|c|c|c|c|c|}
\hline & \multicolumn{2}{|c|}{ Mean fractional anisotropy (SD) } & \multicolumn{2}{|c|}{ Mean diffusivity $\left(\times 10^{-3}\right)(\mathrm{SD})$} & \multicolumn{2}{|c|}{ Mean radial diffusivity $\left(\times 10^{-3}\right)(\mathrm{SD})$} & \multicolumn{2}{|c|}{ Mean axial diffusivity $\left(\times 10^{-3}\right)(\mathrm{SD})$} \\
\hline & Patient & Controls & Patient & Controls & Patient & Controls & Patient & Controls \\
\hline$\overline{C S}$ & $0.300(0.091)$ & $0.349(0.019)$ & $1.000(0.100)$ & $0.920(0.044)$ & $0.800(0.100)$ & $0.720(0.044)$ & $1.300(0.100)$ & $1.240(0.054)$ \\
\hline CC & $0.622(0.149)$ & $0.637(0.051)$ & $1.100(0.100)$ & $0.920(0.044)$ & $0.700(0.200)$ & $0.520(0.044)$ & $1.900(0.300)$ & $1.700(0.052)$ \\
\hline PLIC & $0.555(0.115)$ & $0.639(0.017)$ & $0.900(0.100)$ & $0.840(0.054)$ & $0.600(0.100)$ & $0.480(0.044)$ & $1.600(0.200)$ & $1.520(0.109)$ \\
\hline CWM & $0.655(0.069)$ & $0.596(0.087)$ & $0.800(0.100)$ & $0.780(0.054)$ & $0.500(0.100)$ & $0.460(0.083)$ & $1.500(0.200)$ & $1.400(0.173)$ \\
\hline Pons & $0.364(0.135)$ & $0.427(0.063)$ & $0.900(0.100)$ & $0.800(0.030)$ & $0.700(0.100)$ & $0.580(0.044)$ & $1.200(0.100)$ & $1.200(0.070)$ \\
\hline
\end{tabular}

Legend: CC corpus callosum, CS centrum semiovale, CWM cerebellar white matter, PLIC posterior limb of internal capsule, SD standard deviation 
Table 2 The peculiar clinical phenotype and neuroradiological features of a child harbouring an uncommon 18q22.3q23 interstitial microdeletion

\begin{tabular}{|c|c|c|c|c|c|c|c|c|}
\hline Patients (coordinates) & $\begin{array}{l}\text { Growth } \\
\text { retardation }\end{array}$ & Dysmorphisms & CAA & Dysmielination & $\begin{array}{l}\text { Intellectual } \\
\text { disability }\end{array}$ & CVT & Others & Genes \\
\hline $\begin{array}{l}\text { Present case } \\
\text { Arr cgh18q22.3q23 } \\
\text { (chr18:72887342-75418267) } \\
2.531 \mathrm{Mb}\end{array}$ & Yes & $\begin{array}{l}\text { Epicanthal folds, long nasal } \\
\text { philtrum, thin upper lip, } \\
\text { low-set ears, prominent } \\
\text { frontal bossing and sparse } \\
\text { light hair }\end{array}$ & Yes & Yes & Yes & Yes & Recurrent fever & $\begin{array}{l}\text { ZADH2 } \\
\text { TSHZ1 } \\
\text { SMIM21 } \\
\text { ZNF516 } \\
\text { ZNF236 } \\
\text { MBP } \\
\text { GALR1 }\end{array}$ \\
\hline $\begin{array}{l}{[12]} \\
\text { Arr cgh 18q22.3q23 } \\
\text { (chr18:70508757-74627485) } \\
4.118 \mathrm{Mb}\end{array}$ & Yes & $\begin{array}{l}\text { bitemporal narrowing, } \\
\text { abnormal external ears }\end{array}$ & Yes & Not reported & Yes & No & Cleft soft palate & $\begin{array}{l}\text { ZNF407 } \\
\text { ZADH2 } \\
\text { TSHZ1 } \\
\text { SMIM21 } \\
\text { ZNF516 } \\
\text { ZNF236 } \\
\text { MBP } \\
\text { GALR1 }\end{array}$ \\
\hline $\begin{array}{l}\text { [3] pat.1 } \\
\text { Arr cgh 18q22.3q23 } \\
\text { (chr18:72493281-74110482) } \\
\text { 1.617 Mb }\end{array}$ & No & $\begin{array}{l}\text { prominent } \\
\text { epicanthal folds, depressed } \\
\text { nasal bridge, }\end{array}$ & Yes & No & $\begin{array}{l}\text { Yes } \\
\text { (Speech } \\
\text { delay) }\end{array}$ & Yes & & $\begin{array}{l}\text { ZNF407 } \\
\text { ZADH2 } \\
\text { TSHZ1 } \\
\text { SMIM21 } \\
\text { ZNF516 }\end{array}$ \\
\hline $\begin{array}{l}\text { [13] pat.2 } \\
\text { Arr cgh 18q22.3q23 } \\
\text { (chr18:72.9-75.4) } \\
2.5 \mathrm{Mb}\end{array}$ & No & $\begin{array}{l}\text { hypertelorism, midfacial } \\
\text { hypoplasia, and a broad } \\
\text { mouth with prominent lips }\end{array}$ & Yes & Not reported & No & Yes & $\begin{array}{l}\text { Two sons with the same } \\
\text { clinical features of the } \\
\text { mother }\end{array}$ & $\begin{array}{l}\text { TSHZ1 } \\
\text { SMIM21 } \\
\text { ZNF516 } \\
\text { ZNF236 } \\
\text { MBP } \\
\text { GALR1 }\end{array}$ \\
\hline
\end{tabular}

in choline, creatine, and myoinositol concentrations on MR spectroscopy found in two patients with 18q- syndrome $[22,23]$, as well as in the present patient. These findings suggest functional abnormalities of oligodendrocytes resulting in accelerated myelin turnover associated with astrogliosis. Indeed, MR spectroscopy in patients with Pelizaeus-Merzbacher disease, a representative hypomyelination disorder, typically shows decreased choline due to absence of myelin and mature oligodendrocytes [24].

Diffusion tensor imaging (DTI), an advanced MRI technique assessing the diffusion properties of white matter water in vivo, has been used in the evaluation of several congenital and acquired white matter disorders [25]. On DTI, normal white matter tracts show high diffusion anisotropy (fractional anisotropy, FA) with higher diffusivity in the direction parallel to the fibers (axial diffusivity, $\mathrm{AD}$ ) than in the direction perpendicular to them (radial diffusivity, RD). Increased RD values were detected in mouse models of hypomyelination [20, $26,27]$ and were interpreted as an indicator of myelin density, since the absence of myelin facilitates movement of water molecules perpendicular to the axons. Interestingly, also human DTI studies indicated RD to be the most sensitive among DTI parameters in distinguishing patients with hypomyelinating disorders from controls $[25,28]$. To the best of our knowledge, DTI data have never been reported in patients with 18q- syndrome.
Intriguingly, in the present patient, we did not find a significant increase in RD compared to controls, which reinforces the hypothesis of absent disruption of myelin formation and/or compaction in this disorder. In this regard, the consequences of haploinsufficiency of the $M B P$ gene in humans remain unknown and further investigations are needed to elucidate the role of the astroglia in $18 \mathrm{q}$ - syndrome.

GALR1 gene is involved in regulation of appetite and pituitary hormone secretion, memory, learning, and anxiety [29]. Intriguingly, this gene encodes the galanin receptor GALR1 that mediates the hyperpolarisation of the warm sensitive neurons in the preoptic area of the hypothalamus. Warm sensitive neurons are involved in changes of core body temperature during the fever response [30]. Hence, we could speculate whether the recurrent fevers in the present patient might be secondary to GALR1 deficiency or dysfunction. Although our patient showed teeth abnormalities suggestive of hypohidrotic ectodermal dysplasia, no other clinical signs of this disease were present. Notably ectodermal dysplasia-like findings have been reported only in another child with 18q- syndrome [31]. So far, we are unable to state if the thermic dysregulation in our patient is an occasional finding or a 18q- syndrome-related symptom: obviously further studies on larger case series need to confirm this association.

ZNF516 and ZNF236 are zinc finger transcription factors that could have important roles in the regulation 
of other genes, but their influence in determining the phenotype of our patient is still unclear.

\section{Conclusion}

In conclusion, the clinical features of our patient enlarge the phenotypical spectrum of $18 \mathrm{q}$ deletion syndrome, suggesting that even such small deletion can determine a complex phenotype. Furthermore, the use of advanced brain MRI technique, including DTI and MR spectroscopy, may help to define the type of white matter involvement and therefore improve our knowledge about this interesting syndrome.

\section{Materials and methods Array-CGH analysis}

Array-CGH analysis was performed on the patient and his parents using Human Genome CGH Microarray Kit G3 180 (Agilent Technologies, Palo Alto, USA) with 13 $\mathrm{Kb}$ overall median probe spacing. Labelling and hybridization were performed following the protocols provided by the manufacturers. A graphical overview was obtained using Agilent Genomic Workbench Lite Edition Software 6.5.0.18.

\section{Neuroimaging data}

Diffusion Tensor Imaging (DTI) and MR spectroscopy (MRS) studies were performed during the last MRI followup on a 1.5 Tesla scanner (Achieva, Philips Medical Systems, Best, The Netherlands). DTI data were acquired using a single-shot spin-echo echoplanar imaging diffusion sequence in 32 directions with TR/TE: $9318 \mathrm{~ms} / 71 \mathrm{~ms}$, FOV: $224 \times 224 \times 120 \mathrm{~mm}$, flip angle: $90^{\circ}, 60$ slices, acquisition voxel size: $2 \times 2 \times 2 \mathrm{~mm}$, slice thickness: $2 \mathrm{~mm}$, slice gap: $0 \mathrm{~mm}, 2 \mathrm{~b}$ values of 0 and 800 . DTI data were processed using the FSL software package (Analysis Group FMRIB, Oxford, United Kingdom) [32]. The fractional anisotropy (FA), mean diffusivity (MD), radial diffusivity $(\mathrm{RD})$, and axial diffusivity (AD) values were calculated with a ROI-based approach in bilateral centrum semiovale, posterior limbs of internal capsule, corpus callosum, cerebellar white matter, and pons using MIPAV (https:// mipav.cit.nih.gov/). These values were compared with those obtained from 5 healthy age-matched infants with normal MRI who were studied for headache, first seizure, or minor trauma.

MRS with long and short TE was performed with the point resolved excitation spin-echo sequence (PRESS sequence; long TE: TR/TE = 2000/144 ms; short TE: TR/ $\mathrm{TE}=2000 / 35 \mathrm{~ms}$; voxel size $8 \mathrm{ml} ; 512$ samples, 128 NSA). The measuring voxel was placed in the parietooccipital white matter.

\section{Abbreviations}

(18q-): Deletions of the long arm of chromosome 18; aCGH: High-resolution microarray comparative hybridization; DTI: Diffusion tensor imaging; MRS: Magnetic resonance spectroscopy

\section{Acknowledgments}

We thank the patient's parents for their kind participation and support. We are grateful to Marco Bertorello and Corrado Torello for their technical assistance.

\section{Funding}

This work was supported by "Cinque per mille dell'IRPEF- Finanziamento della ricerca sanitaria" and "Finanziamento Ricerca Corrente, Ministero Salute (contributo per la ricerca intramurale).

\section{Availability of data and materials}

The datasets supporting the conclusions of this article are included within the article. More details are available on request.

\section{Authors' contribution}

MS and DT carried out the neuroradiological studies and drafted the manuscript. SR, RP, PP draft the manuscript. GG, CC and ET performed genetic studies and draft the manuscript. All authors read and approved the final manuscript.

\section{Competing interests}

The authors declare that they have no competing interests.

\section{Consent for publication}

Written informed consent was obtained from the patient for publication of this Case report and any accompanying images. A copy of the written consent is available for review by the Editor-in-Chief of this journal.

\section{Ethics approval and consent to participate}

The current study was performed using peripheral blood of the members of the family treated at the Istituto Giannina Gaslini, Genova, Italy. The parent of the patient gave written informed consent allowing molecular and genetic studies. We didn't request approval by Review Board of our institution, because our study request only classical and molecular cytogenetic analyses. For cytogenetics analyses are sufficient only written informed consent of the parents (DM 21 dicembre 2007).

\section{Author details}

'Laboratorio di Citogenetica, Istituto Giannina Gaslini, L.go G.Gaslini 5, 16147 Genoa, Italy. ${ }^{2}$ Neuroradiology Unit, Istituto Giannina Gaslini, Genoa, Italy.

${ }^{3}$ Istituto Giannina Gaslini, Genoa, Italy.

Received: 9 June 2016 Accepted: 22 September 2016

Published online: 10 October 2016

References

1. de Grouchy J, Royer P, Salmon C, Lamy M. Deletion partielle des bras longs du chromosome 18. Path et Biol. 1964;12:579-82.

2. Cody JD, Ghidoni PD, DuPont BR, Hale DE, Hilsenbeck SG, Stratton RF, Hoffman DS, Muller S, Schaub RL, Leach RJ, Kaye Cl. Congenital anomalies and anthropometry of 42 individuals with deletions of chromosome 18q. Am J Med Genet. 1999:85:455-62.

3. Mark PR, Radlinski BC, Core N, Fryer A, Kirk EP, Haldeman-Englert CR. Narrowing the critical region for congenital vertical talus in patients with interstitial 18q deletions. Am J Med Genet A. 2013;161A:1117-21.

4. Perry BP, Sebold C, Hasi M, Heard P, Carter E, Hill A, Gelfond J, Hale DE, Cody JD. Sensorineural hearing loss in people with deletions of 18q: hearing in 18q-. Otol Neurotol. 2014:35:782-6.

5. Cody JD, Hasi M, Soileau B, Heard P, Carter E, Sebold C, O'Donnell L, Perry B, Stratton RF, Hale DE. Establishing a reference group for distal 18q-: clinical description and molecular basis. Hum Genet. 2014;133:199-209.

6. Cody JD, Carter EM, Sebold C, Heard PL, Hale DE. A gene dosage map of Chromosome 18: a map with clinical utility. Genet Med. 2009;11:778-82.

7. Daviss WB, O'Donnell L, Soileau BT, Heard P, Carter E, Pliszka SR, Gelfond JA, Hale DE, Cody JD. Mood disorders in individuals with distal $18 \mathrm{q}$ deletions. Am J Med Genet B Neuropsychiatr Genet. 2013;162B:879-88. 
8. Linnankivi T, Tienari $P$, Somer $M$, Kähkönen $M$, Lönnqvist $T$, Valanne $L$, Pihko H. 18q deletions: Clinical, molecular, and brain MRI findings of 14 individuals. AM J Med Genet. 2006;140A:331-9.

9. Margarit E, Morales C, Rodriguez L, Monne R, Badenas C, Soler A, Clusellas N, Mademont I, Sanchez A. Familial 4.8 Mb deletion on 18q23 associated with growth hormone insufficiency and phenotypic variability. Am J Med Genet. 2012;158A:611-6.

10. van Trier DC, Feenstra I, Bot P, de Leeuw N, Draaisma JM. Cardiac anomalies in individuals with the $18 \mathrm{q}$ deletion syndrome; report of a child with Ebstein anomaly and review of the literature. Eur J Med Genet. 2013;56:426-31.

11. Eudy JD, Pickering DL, Lutz R, Platt K, Dave BJ, Olney AH, Sanger WG. 18q22. $3 \rightarrow 18 q 23$ deletion syndrome and cleft palate. Am J Med Genet A. 2010;152A:1046-8

12. Heard PL, Carter EM, Crandall AC, Sebold C, Hale DE, Cody JD. High resolution genomic analysis of 18q- using oligo-microarray comparative genomic hybridization (aCGH). Am J Med Genet A. 2009;149A:1431-7.

13. Feenstra I, Vissers LE, Pennings RJ, Nillessen W, Pfundt R, Kunst HP, Admiraal RJ, Veltman JA, van Ravenswaaij-Arts CM, Brunner HG, Cremers CW. Disruption of teashirt zinc finger homeobox 1 is associated with congenital aural atresia in humans. Am J Hum Genet. 2011;89:813-9.

14. Coré N, Caubit X, Metchat A, Boned A, Djabali M, Fasano L. Tshz1 is required for axial skeleton, soft palate and middle ear development in mice. Dev Biol. 2007;308:407-20.

15. Ragancokova D, Rocca E, Oonk AMM, Schulz H, Rohde E, Bednarsch J, Feenstra I, Pennings RJE, Wende H, Garratt AN. TSHZ1-dependent gene regulation is essential for olfactory bulb development and olfaction. J Clin Invest. 2014;124:1214-27.

16. Linnankivi TT, Autti TH, Pihko SH, Somer MS, Tienari PJ, Wirtavuori KO, Valanne LK. 18q-syndrome: brain MRI shows poor differentiation of gray and white matter on T2-weighted images. J Magn Reson Imaging. 2003;18:414-9.

17. Loevner LA, Shapiro RM, Grossman Rl, Overhauser J, Kamholz J. White matter changes associated with deletions of the long arm of chromosome 18 (18qsyndrome): a dysmyelinating disorder? AJNR Am J Neuroradiol. 1996;17:1843-8.

18. Roach A, Boylan K, Horvath S, Prusiner SB, Hood LE. Characterization of cloned CDNA representing rat myelin basic protein: absence of expression in brain of shiverer mutant mice. Cell. 1983;34:799-806.

19. Shine HD, Readhead C, Popko B, Hood L, Sidman RL. Morphometric analysis of normal, mutant, and transgenic CNS: correlation of myelin basic protein expression to myelinogenesis. J Neurochem. 1992:58:342-9.

20. Song SK, Sun SW, Ramsbottom MJ, Chang C, Russell J, Cross AH. Dysmyelination revealed through MRI as increased radial (but unchanged axial) diffusion of water. Neuroimage. 2002;17:1429-36.

21. Tanaka R, Iwasaki N, Hayashi M, Nakayama J, Ohto T, Takahashi M, Numano T, Homma K, Hamano K, Sumazaki R. Abnormal brain MRI signal in 18qsyndrome not due to dysmyelination. Brain Dev. 2012;34:234-7.

22. Häusler M, Anhuf D, Schüler H, Ramaekers VT, Thron A, Zerres K, MöllerHartmann W. White-matter disease in $18 \mathrm{q}$ deletion (18q-) syndrome: magnetic resonance spectroscopy indicates demyelination or increased myelin turnover rather than dysmyelination. Neuroradiology. 2005;47:83-6.

23. Tada H, Takanashi J. MR spectroscopy in $18 \mathrm{q}(-)$ syndrome suggesting other than hypomyelination. Brain Dev. 2014;36:57-60.

24. Takanashi J, Inoue K, Tomita M, Kurihara A, Morita F, Ikehira H, Tanada S, Yoshitome $\mathrm{E}$, Kohno Y. Brain N-acetylaspartate is elevated in PelizaeusMerzbacher disease with PLP1 duplication. Neurology. 2002:58:237-41.

25. Pouwels PJ, Vanderver A, Bernard G, Wolf NI, Dreha-Kulczewksi SF, Deoni SC, Bertini E, Kohlschütter A, Richardson W, Ffrench-Constant C, Köhler W, Rowitch D, Barkovich AJ. Hypomyelinating leukodystrophies: translational research progress and prospects. Ann Neurol. 2014;76:5-19.

26. Harsan LA, Poulet P, Guignard B, Steibel J, Parizel N, de Sousa PL, Boehm N, Grucker D, Ghandour MS. Brain dysmyelination and recovery assessment by noninvasive in vivo diffusion tensor magnetic resonance imaging. J Neurosci Res. 2006;83:392-402

27. Ruest T, Holmes WM, Barrie JA, Griffiths IR, Anderson TJ, Dewar D, Edgar JM High-resolution diffusion tensor imaging of fixed brain in a mouse model of Pelizaeus-Merzbacher disease: comparison with quantitative measures of white matter pathology. NMR Biomed. 2011;24:1369-79.

28. Miller E, Widjaja E, Nilsson D, Yoon G, Banwell B, Blaser S. Magnetic resonance imaging of a unique mutation in a family with PelizaeusMerzbacher disease. Am J Med Genet A. 2010;152A:748-52.

29. lismaa TP, Shine J. In: Richter D, editor. Regulatory Peptides and Cognate Receptors. Heidelberg, Germany: Springer; 1999.
30. Eberwine J, Bartfai T. Single cell transcriptomics of hypothalamic warm sensitive neurons that control core body temperature and fever response Signaling asymmetry and an extension of chemical neuroanatomy. Pharmacol Ther. 2011:129:241-59.

31. Zannolli R, Pierluigi M, Pucci L, Lagrasta N, Gasparre O, Matera MR, Di Bartolo RM, Mazzei MA, Sacco P, Miracco C, de Santi MM, Aitiani P, Cavani S, Pellegrini L, Fimiani M, Alessandrini C, Galluzzi P, Livi W, Gonnelli S, Terrosi-Vagnoli P, Zappella M, Morgese G. 18q-syndrome and ectodermal dysplasia syndrome: description of a child and his family. Am J Med Genet A. 2003;116A:192-9.

32. Smith SM, Jenkinson M, Woolrich MW, Beckmann CF, Behrens TEJ, Johansen-Berg H, Bannister PR, De Luca M, Drobnjak I, Flitney DE, Niazy R, Saunders J, Vickers J, Zhang Y, De Stefano N, Brady JM, Matthews PM. Advances in functional and structural MR image analysis and implementation as FSL. Neurolmage. 2004;23(S1):208-19.

\section{Submit your next manuscript to BioMed Central and we will help you at every step:}

- We accept pre-submission inquiries

- Our selector tool helps you to find the most relevant journal

- We provide round the clock customer support

- Convenient online submission

- Thorough peer review

- Inclusion in PubMed and all major indexing services

- Maximum visibility for your research

Submit your manuscript at www.biomedcentral.com/submit
) Biomed Central 